\title{
FLUXos E CAMinhos NA CULTURA VisuAL
}

\author{
Moisés de Lemos Martins \& Zara Pinto-Coelho
}

Ao longo dos últimos anos, as práticas de produção de imagens (por exemplo, fotografar, filmar, editar, desenhar) têm sofrido múltiplas transformações relacionadas com o crescente diálogo entre tecnologias visuais digitais, plataformas de redes sociais, vídeos/sites e aplicativos de partilha de imagens. Este diálogo está a possibilitar o desenvolvimento de novas formas de visualidade e, consequentemente, de novas práticas, dentro e através de uma variedade de campos, online e offline.

Neste volume, interrogamos criticamente a amplitude e a riqueza dessas mudanças, como estão incorporadas na sociedade e na vida do quotidiano, as suas implicações sociais, políticas, culturais, estéticas e poéticas e o seu impacto na redefinição contínua do funcionamento do visual e do seu lugar nas sociedades contemporâneas.

$\mathrm{Na}$ designação do tema deste número da revista, dedicado à cultura visual, incluímos a figura do fluxo, que é uma metáfora da vida. Fluxo e vida tendem ambos a desenvolver-se na tensão entre equilíbrio e desequilíbrio, entre harmonia e desarmonia. Vivências e experiências são fases da corrente que é a duração de uma vida.

A experiência visual, hoje, na era tecnológica que é a nossa e onde se decide o humano (Martins, 2007), é mais do que nunca fluxo de luz e de sensibilidade. Mas a continuidade de um fluxo não pode garantir-nos nunca a estabilidade. Sempre que conseguimos algum equilíbrio, logo espreita a ameaça de nova instabilidade. De facto, não existe o continuum de um fluxo. Assim como também não acontece o continuum de uma vida.

Organizámos o número em cinco grandes secções. A primeira integra artigos que teorizam o visual, mas também o aplicam a formas culturais visuais tangíveis. A segunda reúne testemunhos e relatos de percursos pessoais de atores ligados às artes plásticas e visuais no Brasil. A terceira apresenta uma nota onde é feita uma breve revisão da obra de uma artista plástica brasileira e duas revisões de obras sobre imagem visual. A quarta dá conta de uma entrevista realizada a um cineasta moçambicano. A quinta e última parte, a Varia, inclui dois ensaios com temáticas diversas.

Relativamente à primeira secção, reunimos os artigos temáticos em três grandes grupos. Nos artigos incluídos no primeiro grupo são discutidas as implicações sociais e culturais da presença e dos usos quotidianos das imagens eletrónicas. Os artigos agrupados no segundo, são relativos às artes visuais e digitais/computacionais, ao seu registo, estudo e criação. Os artigos que integram o terceiro grupo, e parte final da secção dedicada aos artigos temáticos, exploram a cultura visual nos contextos da educação e da infância.

É sabido que na base da socialidade contemporânea estão os episódios do quotidiano e que nessa experiência do mundo o visual adquiriu um papel central com as mudanças sociais e tecnológicas vividas na sociedade global contemporânea. Referimo-nos 
ao forte vínculo existente entre a cultura visual atual e as dinâmicas acentuadas de globalização, tecnologização e digitalização do quotidiano.

A abrir os artigos temáticos, temos o texto de Fábio la Rocca. Recordando a trajetória atribulada da imagem e o papel do cinema e da fotografia na criação de uma nova visão, o autor defende que vivemos um novo tipo de civilização da imagem, onde a vida social e a experiência prática da vida quotidiana são cada vez mais condicionadas pela presença e uso massivo de imagens. Com base nesta hipótese, mostra-se como é que esta nova prática ou forma de ver e pensar através das imagens tem alterado os processos de compreensão e de perceção da nossa relação com a realidade social, com os outros e com nós mesmos, chamando para a discussão o caso do Instagram e das selfies.

Vincenzo Susca transporta-nos para um universo particular, para o que acontece quando o erotismo entra no quotidiano, oleado por uma nova economia sexual e promovido pelos "ecrãs escaldantes dos sites pornográficos", que diz serem "simultaneamente laboratórios e matadouros de carne fresca, em plena renovação e substituição, virada do avesso e colada às peças". Como bem assinala José Augusto Mourão, noutro contexto, "parece irónico falar de 'carne' quando estamos a dizer adeus à carne. Enfim, falar ironicamente não é mentir. (...) Dizer adeus ao corpo não é dizer que o corpo desapareceu, mas que provavelmente está a mudar de cara ou de figura (Mourão, 2002, p. 82)". Vincenzo Susca, por sua vez, defende que atualmente "a carne transformou-se em logos" e que se tornou o significado principal do imaginário contemporâneo. Para avaliar esta mudança, vista pelo autor como sendo de natureza antropológica, é feita uma análise das caraterísticas da paisagem porno, entre padrões básicos e traços identitários atuais. Destacam-se as redes sociais pornográficas e eróticas, como o Youporn.com, e consideram-se as diversas atualizações que emergem deste exemplo, em articulação com softwares e apps, como o Tinder ou Happn, técnicas geolocalizadas que permitem uma grande abrangência de movimentos, entre fluxos metropolitanos e na criação de afinidades mobilizadas pelo erotismo. Aos olhos do investigador, o porno da web 2.0, um porno que se tornou exclusivamente visual, não deve ser abordado como uma mera indústria de entretenimento, mas como um "paradigma existencial do nosso quotidiano: um estilo de vida forjado em chamas de prazer".

As mudanças no modo como as imagens são capturadas, geradas, processadas e distribuídas, dialogam diretamente com o modo com as percebemos e reprogramam hábitos de ver. Com a popularização do vídeo pela internet, a difusão acelerada da tecnologia móvel, em especial dos smartphones, e a ubiquidade das redes de bandas largas, abriram-se possibilidades de novas formas de criação e uso de produtos audiovisuais (como é o caso dos videosclipes interativos, Barboza, 2015, ou dos fanvids, Costa-Sánchez \& Piñeiro-Otero, 2012).

Humberto de Campos Rezende e João Victor Boechat Gomide destacam no seu artigo o exemplo das séries televisivas e o fenómeno do binge watching, ou maratona de consumo consecutivo de vários episódios, um fenómeno potenciado pelo acesso às mesmas por plataformas mundiais, como é o caso da Netflix. De acordo com os investigadores, trata-se de um comportamento que não é novo, mas que é agora explorado de 
uma forma profissional pela TV, empenhada na produção industrial de séries "viciantes", voltadas para esse tipo de audiência. A propósito deste fenómeno, que como qualquer fenómeno novo tem recebido atenção positiva e negativa nos média, são debatidos, por um lado, o comportamento ativo deste tipo de espectador, por outro, as alterações que se têm vindo a registar na forma de se contar uma história.

No capítulo seguinte, Angie Biondie fixa-se noutra das práticas que povoam o nosso quotidiano: a dos autoretratos digitais e sua partilha através das redes sociais. As redes sociais são espaços de interação e afetividade e essa interação tem, na maior parte das vezes, uma forte componente visual. Partilhar imagens através de aplicações de redes sociais é uma prática recorrente que confere à experiência quotidiana dos seus utilizadores novos contextos de visibilidade social e de conexão. Na sua banalidade quotidiana, a selfie é um objeto interessante, através do qual podemos compreender as mudanças nas formas comunicativas na idade da internet e das redes sociais. Fotografar-se individualmente ou num coletivo, seja em locais públicos, seja em locais de acesso mais restrito ou até íntimo, e descarregar a imagem no Instagram ou no Facebook, tornou-se uma ação social. Aclamadas por uns, criticadas por outros, as selfies são parte fundamental de novos reportórios comunicativos, centrados na produção da identidade e na sua gestão. Propondo-se pensar os sites de redes sociais como espaços de conversação, Angie Biondie privilegia no exercício de análise imagens recentes, veiculadas pelo Instagram, entre 2015 e 2016, através da hashtag de uma campanha internacional contra a violência sexual e de género, onde os sujeitos se declaram vítimas, a partir das histórias pessoais de violência que compartilham e dos autorretratos, selfies. Interessa-lhe mostrar o aspecto seletivo que há neste tipo de exposição, através de autorretratos, como uma forma de atestação pessoal, legítima e genuína. Mostra-se que as selfies funcionam, quer para assegurar o valor de sinceridade das declarações, quer para promover a interação com e entre os outros usuários.

Se é verdade que a textura da vida quotidiana está marcada pelo rápido fluxo de imagens, em especial em espaços urbanos, onde "em muito do que fazemos e do que é feito connosco, do que percecionamos e do que pensamos, dificilmente conseguimos estar separados dos ecrãs" (Neves \& Pinto-Coelho, 2010, p. 6), também é certo que este aparelhamento tecnológico e estético se faz sentir noutros contextos, nomeadamente nas práticas artísticas e científicas. A ubiquidade da tecnologia e o embaratecimento dos custos transformaram o fazer artístico e a produção digital.

Adérito Fernandes Marcos discute no seu artigo a emergência da arte digital e das suas diversas variantes, tais como a arte computacional e a média-arte digital. Defende que a estética deste arte não se deve confinar à produção de estímulos de prazer e emoções fugazes, mas deve ter como finalidade "promover o questionamento e a reflexão em torno dos temas fundacionais da nossa razão de existir como individuo, sociedade, humanidade e como universo". Assumindo que a forma como consumimos arte e cultura é influenciada fortemente pelos meios digitais, conjugados com as tecnologias da informação e da comunicação que permitem o seu processamento e comando, apresenta, na sua discussão, três exemplos de artefactos digitais/computacionais. Antes de mais, 
refere o artefacto Tapete Interactivo "Óbidos/Oppidum", realçando o facto de estabelecer novas linhas de desenvolvimento e reflexão na área do design de moda e na utilização do corpo como mediador de intervenção em arte e cultura digital. Convoca, depois, o artefacto "Escultura Présence", onde o utilizador produz composições sonoras eletrónicas, que o identificam de forma singular, a partir dos movimentos corporais que realiza, e que são registados juntamente com o conteúdo sonoro. Quanto ao último artefacto assinalado, "Entre o Sagrado e o Profano nas Festas de S. João d'Agra", Adérito Marcos mostra como é desenvolvida uma representação pictórica, dinâmica, que representa o local da romaria, que se vai alterando em resultado da interação do utilizador-fruidor.

Com a gigantesca rede de comunicação representada pela internet - os seus recursos multimediáticos e hipertexto - e a democratização do acesso a tecnologias digitais de registo em imagem (telemóveis, câmaras fotográficas e de vídeo), têm crescido, a uma escala até aqui desconhecida, a produção individual de objetos de natureza visual e audiovisual e a sua disseminação, o que contribui para a emergência de novos fenómenos e de novas práticas, também no campo científico.

Tomando a figura do flâneur, de Charles Baudelaire, como representativa do entendimento que partilham da cultura visual contemporânea e do espaço e lugar, Maria da Luz Correia, Helena Pires e Pedro Andrade apresentam a Passeio, que é uma plataforma de arte e cultura urbana, concebida no âmbito do Centro de Estudos de Comunicação e Sociedade da Universidade do Minho. Contextualizando a apresentação desta plataforma, no quadro das obras de Walter Benjamin, Roland Barthes, Mirzoeff e Simmel, entre outros, os autores revelam vários aspetos da Passeio. Referem-se, antes de mais, o seu objeto, que são as ruas da cidade, no que respeita à arquitetura, graffiti, música, teatro, animação de rua, desporto urbano, artesanato, comércio tradicional, publicidade e vitrinismo. Assinalam, também, o seu objetivo, que é o de contextualizar as ações quotidianas, que acontecem nas ruas. Pronunciam-se, ainda, sobre as opções teóricas e metodológicas que estruturam esta plataforma de arte e cultura urbana. E, finalmente, salientam os seus vários eixos de ação, a saber, investigação e formação, arquivo e divulgação, colaboração e extensão.

No artigo seguinte, incluído na última parte da secção dedicada aos artigos temáticos, a obra de Walter Benjamin continua a ser fonte de inspiração, neste caso para Norval Baitello Junior e Tiago da Mota e Silva, que extrapolam para o consumo dos média eletrónicos na atualidade o significado do objeto lúdico em Benjamin, supondo que o confronto imaginação-imaginário ocorre no âmbito do uso de tablets em sala de aula. Numa pesquisa realizada numa escola particular de São Paulo, sendo o universo constituído por estudantes do primeiro ano do Ensino Fundamental, entre 6 e 7 anos, foram observados e registados comportamentos ambivalentes no uso dos tablets. No uso do tablet e na ação de brincar com jogos, não apenas ocorre o reforço do programa social da escola, como, por outro lado, ocorre a sua reinvenção. Para compreender este embate, os autores recorrem aos conceitos de ludus e de paidia. E assim ludus surge como adestramento da paidia, nos espaços de jogo na cultura, assim também o uso do conceito de círculo mágico descreve a experiência de estar em ambientes comunicacionais, 
e a utilização dos conceitos de imaginação e imaginário permite que o imaginário surja como adestramento da imaginação. Norval Baitello Júnior e Tiago da Mota e Silva sugerem que o exemplo das crianças revela facetas que podem ser averiguadas noutros contextos de consumo mediático, em particular aqueles que são de caráter aditivo, uma vez que a "ecrã-dependência, afinal, não é outra coisa senão um problema de imaginação: imaginar com imagens que não são nossas próprias imagens".

Por sua vez, no seu artigo, Anna Clara Marotti Magalhães e Leticia Maia Dias falam-nos de imagens que são as nossas, as de gente comum, assim como da preservação da sua memória na forma digital, enquanto património, que pode ser trabalhado pelos professores da área da educação patrimonial para promover a integração e a aceitação da diversidade. Dedicado ao Museu da Pessoa, um projeto totalmente digital, que proporciona, não apenas a interação, mas também a participação do internauta no acervo do museu, o que implica que qualquer cidadão do mundo pode ter a sua história retratada no site (Oliveira, 2007; Simões \& Almeida, 2003), este artigo realça a importância do Museu da Pessoa para combater aspetos da mentalidade colonial que persistem em certos setores sociais no Brasil. Este combate passa pela ressignificação da herança cultural de certos grupos, como no caso das comunidades indígenas e quilombolas, e da sua participação no processo de construção da identidade nacional.

A encerrar os artigos temáticos, temos a proposta de Fernanda Mendes Cabral Coelho e Adelaide Alves Dias para pensarmos infâncias e imagens de crianças, na confluência dos estudos culturais e da cultura visual com a sociologia da infância. A partir de três narrativas imagéticas, produzidas a partir de imagens de crianças, integradas em pesquisas académicas e científicas no Brasil, são colocadas em relevo as diferenças entre duas situações distintas: por um lado, como eram e são representadas as crianças, e por outro lado, como essas representações se repercutem nas compreensões das culturas infantis de cada época (da idade média aos dias de hoje). Ao comparar as infâncias retratadas, as autoras sublinham que as marcas do "homúnculo" ainda estão bem presentes nas culturas visuais do século XXI.

$\mathrm{Na}$ secção a que chamamos "Testemunhos-Percursos Pessoais", incluímos dois relatos, que se situam no panorama das artes visuais e plásticas do Brasil.

Assente no pressuposto de que o artista deve ter um papel político, de intervenção na sociedade, Jeanine Toledo, relata-nos a sua experiência pessoal, destacando duas das exposições que realizou no Recife, onde dá a ver Uns e Outros, de 2003, e a Lente Turva, de 2007, afinal, como diria Martine Xiberras (2010, p. 29), "o ecrã espesso formado pelo os arquétipos ligados aos imaginários de género, invisíveis aos olhares das culturas que os partilham (Xiberras, 2010, p. 29)".

Entretanto, Maria do Carmo Nino relata-nos a sua experiência em diferentes setores ligados às artes plásticas, onde tem desempenhado vários papéis - produtora, curadora, analista, professora -, dando especial destaque a dois dos seus trabalhos enquanto curadora: Projeto MAMÃE e a exposição ContidoNãoContido, ocorrida no Museu Aloísio Magalhães (MAMAM), aberta ao público de março e setembro de 2010.

A encerrar a discussão em torno das problemáticas suscitadas pelo tema condutor deste número da revista, constam dois tipos de revisões. Uma delas é dedicada à arte 
contemporânea brasileira, com Ana Cármen Palhares a traçar o perfil da artista Jeanine de Lima Toledo. A outra constitui, na verdade, uma presença clássica em revistas académicas, e está centrada na revisão de obras científicas dedicadas à imagem visual. São duas as recensões. Isabel Macedo revê a obra Teoria do acto icónico, de H. Bredkamp, conhecido historiador de arte, publicada pela Editora KKYM e traduzida por Artur Mourão. E Zara Pinto-Coelho apresenta-nos Uma breve história da imagem, de Michel Melot, bibliotecário francês. Trata-se de uma obra publicada em França, em 2007, pela Edições L'Oeil Neuf, e em Portugal, em 2015, pelo Centro de Estudos de Comunicação e Sociedade e a Editora Húmus, tendo sido Aníbal Alves o tradutor.

$\mathrm{Na}$ secção dedicada às entrevistas, Ana Cristina Pereira entrevista João Ribeiro, cineasta moçambicano, a propósito da sua obra e da sua história de vida, deixando clara a estreita relação entre estas e os meandros da história do cinema moçambicanor.

Fechamos este número da revista com dois artigos na secção Varia. Alexandre B. Weffort, em diálogo com Moisés de Lemos Martins, na obra Crise no castelo da cultura. Das estrelas para os ecrãs, publicada em 2011, disserta sobre o tema da dialética e questiona algumas das conclusões propostas na obra referida. Entretanto, Joaquim Costa defende que, na nova economia de mercado, religião e economia são universos paralelos que se entrecruzam na sua ambição expansionista e universalista, na linguagem com que constroem o mundo, tornando-se "a infraestrutura somática das sociedades que conquistaram".

\section{REFERÊNCIAS BIBLIOGRÁFICAS}

Costa-Sánchez, C. \& Piñeiro-Otero, T. (2012). Espectadores o creadores? El empleo de las tecnologías creativas por los seguidores de las series españolas. Comunicação e Sociedade, 22, 184-204.

Barboza, E. M. R. (2015). Narrativas digitais: um estudo sobre os videoclipes interativos da banda Arcade Fire. Comunicação e Sociedade, 27, 369-385.

Martins, M. L. (2011). Crise no castelo da cultura. Das estrelas para os ecrãs. Coimbra: Grácio.

Martins, M. L. (2007). Introdução - A época e as suas ideias. Comunicação e Sociedade, 12, 5-7.

Mourão, J. A. (2002). A carne do imaginário. Ironias do aquém e do além. Comunicação e Sociedade, 4, 81-95.

Neves, J. \& Pinto-Coelho, Z. (2010). "Em direcção ao vazio ou a qualquer coisa": os ecrãs e as ligações quotidianas sociotécnicas. Comunicação e Sociedade, 17, 5-7.

Oliveira, J. C. (2007). O museu digital: uma metáfora do concreto ao digital. Comunicação e Sociedade, 12, 147-161.

Schefer, R. (2016). Mueda, memória e massacre, de Ruy Guerra, o projeto cinematográfico moçambicano e as formas culturais do Planalto de Mueda. Comunicação e Sociedade, 28, 27-51.

Simões, A. \& Almeida, J. (2003). Histórias de vida + Processamento estrutural = Museu da Pessoa. Retirado de http://hdl.handle.net/1822/629/

Xiberras, M. (2010). Figures d'Eros: mythes et cultures. Comunicação e Sociedade, 18, 27-40.

\footnotetext{
' Para conhecer de forma mais detalhada a singularidade da política cinematográfica moçambicana, ver Schefer (2016).
} 


\section{NOTAS BIOGRÁFICAS}

Moisés de Lemos Martins é Professor Catedrático do Departamento de Ciências da Comunicação da Universidade do Minho, onde ensina e investiga em sociologia da comunicação e da cultura, estudos culturais, comunicação intercultural, e semiótica social. Dirige o Centro de Estudos de Comunicação e Sociedade (CECS), que fundou em 2001.

E-mail: moisesm@ics.uminho.pt

Centro de Estudos de Comunicação e Sociedade

Instituto de Ciências Sociais da Universidade do Minho, Campus de Gualtar, 4710057 Braga, Portugal

Zara Pinto Coelho é Professora Associada do Departamento de Ciências da Comunicação da Universidade do Minho, onde ensina sociologia da comunicação, estudos do discurso e semiótica social. Os seus interesses de investigação incluem as teorias do discurso e as suas aplicações críticas aos estudos dos média e aos estudos culturais, em tópicos relacionados com poder e ideologia, por exemplo, em discursos de participação pública, na cobertura jornalística da saúde ou na interseção do género com a heterossexualidade.

E-mail: zara@ics.uminho.pt

Centro de Estudos de Comunicação e Sociedade

Instituto de Ciências Sociais da Universidade do Minho, Campus de Gualtar, 4710-057 Braga, Portugal 